\title{
Consilience, Abduction, and Mimetic Theory: An Epistemological Inquiry into René Girard's Interpretation of the Oedipus Myth
}

\author{
Marian TATARU \\ West University of Timisoara
}

\begin{abstract}
The purpose of this paper is to describe the evolution of the fundamental guidelines according to René Girard's interpretation of the Oedipus myth. After close examination, it appears Girard's methodology is based on four complementary levels: (1) the common-sense tracking of sacrificial substitutions; (2) the careful analysis of symmetries and dissymmetries in mythical texts; (3) the identification of cross-cultural and historical persecution stereotypes; (4) the application of the common standard of evidence (i.e. guilty beyond a reasonable doubt) for criminal conviction. Throughout the paper, we will show that Girard's approach bears strong resemblance with William Whewell's method of consilience as well as Charles Sanders Peirce's views of the historical sciences.
\end{abstract}

\section{Keywords}

René Girard; Oedipus; Sophocles; William Whewell; Charles Sanders Peirce; scapegoat mechanism; consilience; abduction.

\section{Introduction}

Nearly all the males of the Labdacian family tree were fated, and deservedly so, to be victims to a greater, unstoppable, Godly power. This is what the mythology tells us. The history of the family is a history of violence. This can be seen beginning with Cadmus, founder of Thebes and the ancestor of Oedipus. The sons of Oedipus, known as the enemy brothers, Eteocles and Polynices, are again a prime example of the violent patterns this family was destined to suffer. However, should we not read the whole story through an atheist perspective? Should we not say that gods and curses are only the symbolic means for concealing the sad truth of human violence?

This is an Open Access article distributed in accordance with the Creative Commons Attribution Non Commercial (CC-BY-NC-ND 4.0) license, which permits others to copy or share the article, provided original work is properly cited and that this is not done for commercial purposes. Users may not remix, transform, or build upon the material and may not distribute the modified material (http:/ / creativecommons.org/ licenses/by-nc/4.0/) 
The son turned father thinks he can escape from the circle by redoubling the violence that was first directed against himself. It is in order to break with the past that each time a new cycle of misfortune is set in motion. ${ }^{1}(O U, 32)$

Now, one may retort that vindictive demystifications are not compatible with serious rules of text interpretation, and further state that ultimately, keep a neutral attitude towards ancient myths. For even if we do not believe in the ancient stories, specific inferences of their truth or falsity are automatically condemned to be insecure or ill-founded. Yet, René Girard challenged this notion. According to him, there is a concealed lie at the core of the myth, where the crude reality of human violence is both hidden and sacralized. Myths are the covered-up stories, the literary veiling of the scapegoat mechanism, the distorted scenario of a collective murder of a single victim who saved the community from its state of crisis. This is exactly, contended Girard, how the myth of Oedipus should be interpreted and analyzed. This standpoint might sound arbitrary or abrupt. Our first impression is that Girard transgressed the rules of sound methodology. His outlooks, indeed, went far beyond what the common hermeneutic approach would allow us. Nonetheless, we should also note our rather uncritical attitude regarding Sophocles' tragedy, Oedipus the King. For what if, instead of carefully reading the tragedy, classical interpretations (including Freud's) simply took for granted its conclusions? Oedipus is guilty of incest and parricide. The regicide, the unholy human being must be banished from Thebes, the city whose people endure the divine and painful curse of the plague. To overstate the end of the play is to underestimate the plausibility of a persecution story where one man received the blame for all the Thebans' misfortunes.

However, this is not reason enough to accept Girard's interpretation. If his works on the Oedipus myth were simply about the possibility of an alternative and hidden explanation, then his reasoning would hardly be different from many recent conspiracy theories. It is therefore necessary to dismiss summaries and to account for the methodology that Girard patiently developed. Our aim in this paper is to show that, through his study of the Oedipus myth, Girard articulated four different and independent levels of inquiry. At the start, Girard gained his intuition of the concealed scapegoat mechanism by linking the common, and evident, tendency of human violence to seek surrogate victims with his novel readings of the Greek tragedies in terms of symmetries and dissymetries. To explain, that is the idea that the increasing, contagious, and chaotic sameness of rivals in the context of violent mimicry can only be stopped through a (sacrificial) process of differentiation. In 1982, with his essay Le Bouc émissaire (The Scapegoat ${ }^{2}$ ), Girard began to inquire into the structural similarities between myths and texts of medieval persecution. Thus, he managed to expand his methods and hypotheses on more cross-cultural and cross-historical levels. However, Mark Anspach ${ }^{3}$ showed that a third methodological axis in Girard's works can be considerably supplemented, namely, what we would call the legal or investigative approach in which inferences drawn from the collected evidence are withheld to prove guilt beyond a reasonable doubt. In the last analysis, we will see that Girard's approach can be situated in between William Whewell's method of consilience and Charles Sanders Peirce's views of the historical sciences.

\footnotetext{
${ }^{1}$ René Girard, Oedipus Unbound: Selected writings on Rivalry and Desire, ed. Mark R. Anspach (Paolo Alto: Stanford University Press, 2004), 32. See also p. 34-35 for Girard's comments on Eteocles and Polynices.

2 René Girard, The Scapegoat (Baltimore: John Hopkins University Press, 1986).

${ }^{3}$ Mark R. Anspach, "Introduction: Imitating Oedipus", in Oedipus Unbound, vii-liv.
} 


\section{From the "Novelistic Truth" to the Scapegoat Hypothesis}

In this first section, we will briefly discuss Girard's first study dedicated to Sophocles' play. In this 1965 paper the absence of the scapegoat hypothesis is conspicuous. We will then cover the first pivotal aspects of Girard's methodology, namely the sacrificial substitution lecture and the "structural" symmetry and dissymmetry approach, which he outlined a few years later. In brief, our aim will be to stress the similarities and differences between Girard's first study of the Oedipus myth and his later works.

\section{A. "From Novelistic Experience to the Oedipal Myth"}

In his first book, Deceit, Desire and the Novel, Girard introduced his well-known theory of triangular desire. According to him, desire is directed towards objects by the imitation of the desire of the Other, or the model or mediator in Girard's own terminology. In the specific context of "double mediation", each agent becomes a model-obstacle for the other. While each agent aims to prove the anteriority or authenticity of his desire with respect to the other, mimicry operates below the agents' consciousness, making this process frighteningly more similar between the two than it would otherwise be, that is, if each were to recognize the shared desire.

Thus, at the beginning of the 1960s, Girard put into question the classic dichotomy of Self/Other at the level of human desire. It is this pivotal topic that he would explore again in his first study of Sophocles' play, "From Novelistic Experience to the Oedipal Myth". In 1965, Girard maintained the idea that doubling, the idea of unconscious mirror play in an inter-relational dynamic of human desires, is the key intuition of great novelists such as Stendhal, Dostoyevsky, and Proust. The tour de force of such great novelists resides in their ability to show that the Self has to acknowledge its perfect similarity with the Other on the playground of desire. For these novelists, says Girard, there can be no question of the romantic conception of the Self (based on the idealistic ideas of contemplation, authenticity and self-sufficiency). The truth about the Other, turns out to be the truth about myself. As Girard puts it: " ... to discover that this wicked Other and the Self are one, means discovering the Same in what once passed for absolute Difference, it means unifying reality. But first of all means dying." (OU, 9).

We thus enter the painful and demanding realm of the "novelistic experience". For the recognition of the sameness of Self and Other is not a pleasing experience at all. In Girard's writings, the sameness of human beings always appears as the most unbearable reality. This aspect remains crucial in this first encounter with the Oedipus myth. Sophocles, just as the great aforementioned novelists, puts into question the illusion of difference between Self and Other. Oedipus wants to appropriate the being of his mediator and father Laius. According to Girard, the essential feature of Sophocles' play is to highlight the illusion of difference that separates father and son:

The son is a faithful copy of the father, his mirror-image. The conflict between the two men does not feed on differences, as all thinking in line with common sense would have it, but on resemblances continually elicited by the identity of aims and the convergence of desire. The logic of desire must be distinguished from the logic of ideas. Two contradictory ideas are always, of course, two different ideas. By contrast, for two desires to oppose and to contradict one another, they must be identical. (OU, 28).

Eventually, Oedipus will make the choice of blindness after discovering that he is nothing more than his father's monstrous double. Blindness appears as a sign, this sign being a glimpse into the truth of human relations. Therefore, at Colonus, Oedipus was 
welcomed as a man of wisdom $(O U, 14)$. In brief, Girard reads the tragedy as "a struggle against the double" which "culminates in the novelist's defeat" $(O U, 13)$.

As we now see, in this first study of Oedipus Rex, Girard does not mention a single time the existence of a scapegoat mechanism. The killing of the father and the incestuous relationship with the mother are not yet subjected to the critical scrutiny that will become obvious in Violence and the Sacred. We could therefore say that, in this first step, Girard approaches the Greek tragedy with more literary sensibility than anthropologic sensibility.

\section{B. Towards the scapegoat bypothesis}

Let us now try to see what were, from a methodological point of view, the missing elements in Girard's deconstruction of the Oedipus myth. "Symmetry and Dissymmetry in the Myth of Oedipus" (1968) and "Oedipus Analysed" (1970) show an evolution worth being considered. At first glance, the gap separating these two studies from the 1965 paper is impressive (suddenly, all the decisive seeds of Violence and the Sacred can be discovered). However, as we shall see, one may also consider that Girard extended the scope and degree of his first intuitions.

Understandably, Girard needed to take into account the general tendency of violence to seek surrogate victims. In order to revolutionize the reading of Sophocles' play, Oedipus' destiny has to be understood from a different position. This is done by being replaced in a sacrificial substitution mechanism in which the misfortune of a single person can alleviate the pain and chaos of the Theban population. As Girard will clearly remind us years later, the idea of sacrificial substitution immediately makes sense and does not need the mimetic theory to sustain itself ${ }^{4}$. Girard might even say that this is mainly a matter of common sense. For we should not forget that Sophocles' play starts with the threat of the Theban plague. The epidemic that is due to the crimes of incest and parricide that had defiled the city made Thebes a city needing to be decontaminated. Now, this dramatization cannot be considered as a consistent natural law. Even if Oedipus is guilty of incest and parricide, he cannot be the cause of a contagious disease ${ }^{5}$. Therefore, from the perspective of sacrificial substitution and independently of other elements of Girard's theories, we have strong reasons to believe that Oedipus, indeed, was a scapegoat.

But the question, then, is to know how Girard's insights on imitation and desire, which were already developed in his 1965 paper, could sustain the scapegoat hypothesis at a deeper level. During the seven years separating his first study of Oedipus from Violence and the Sacred, Girard developed what we may define as a more global and structural approach of Greek tragedy. The question of the demystification of the difference between Self and Other remains central. In tragic plays, this demystification can be seen in the symmetries with respect to all the character's mutual relations. It is, for instance, the opposition between Oedipus and Creon who are identical with respect to their shared desire for political power $(O U, 63)$. It is also the opposition between Oedipus and Tiresias, identical in their rivalry for wisdom and clairvoyance $(O U, 82-83)$. It is, generally speaking, a perpetual ebb and flow of accusation which betrays the fundamental sameness of all the characters in Sophocles' play. Symmetry, thus, designates the truthful or, to put it differently, the nonillusory elements of the play. Symmetry, as Girard frequently reminds us, is an essentially non-Manichean component of Greek tragedy. From this perspective, characters cannot be

\footnotetext{
${ }^{4}$ Mark R. Anspach, Edipe Mimétique (Paris : L’Herne, 2010), "Entretien avec René Girard”, 15-17.

${ }^{5}$ Girard already expresses this common-sense skepticism in 1968: "The hero gathers upon himself all the impurities circulating in the city. His departure from Thebes cures the citizens of the 'plague.." $(O U, 60)$.
} 
distinguished as good or bad, and even the supposed uniqueness of their psychological traits eventually appears as a lure. Therefore, the principle of symmetry should lead us to conclude that there is in Oedipus a perfect similarity with respect to the other characters.

However, we also know that this conclusion is not directly compatible with the one in Sophocles' play. Oedipus' exile from Thebes designates the structural aspect of dissymmetry which reinstates the illusion of difference between Self and Other. On the narrative level, dissymmetry should be considered as a deceptive element. But this sole element is insufficient if we want our suspicion to rest on a solid basis. What we need to understand is that the generalization of human conflict is increasing in the characters' symmetry and effacing the cultural and conventional differences separating them. This is Girard's idea of undifferentiation, that violence spreads in a contagious way through the whole community. This mimetic spreading of violence only depends on the behavior and responsibility of human agents, but it also remains beyond their consciousness. For them, the global chaos appears to come from outside: it is either an epidemic or a godly curse, or perhaps both. This is, according to Girard, the true meaning of the Theban plague in Sophocles' play: "The mythic plague is the passive contagion of desire and hatred which, spreading from one person to the next, shakes the very foundations of society." (OU, 43).

At this point, the two methodological approaches, the former based on the commonsense identification of sacrificial substitution, the latter based on a more structural reading of the play, will appear as convergent. For it is solely Oedipus' character on which the symbolism of undifferentiation will be developed. Oedipus will appear as the personification of undifferentiation. Incest and parricide, far from being culturally repressed desires as Freud contends, are a particularized way of expressing the general idea of social chaos. Both transgressions, indeed, "culminate in disorder and sterility in marriage and kinship, in all the fundamental processes of human existence" (OU, 85). Oedipus is then the only character in Sophocles' play who can be defined as conjunctly symmetrical and dissymmetrical. He stands for the radical symmetry of human conflict spreading in Thebes, and for dissymmetry in that he is the symbol of the general and violent chaos. In other words, a single person appears as a substitute for the misfortunes of the whole community. As Girard puts it: "The patricide is the dissymmetry accomplished at the expense of the scapegoat, but this dissymmetry is but an extreme form of symmetry." (OU, 65).

It should be noted that these first approaches of the Oedipal myth give way to future developments in Girard's work. If incest and parricide are accusatory symbols of undifferentiation, then we need to see if they have the same status, or functions, in other myths or rituals (as already understood in Violence and the Sacred, wherein Girard substantiated this hypothesis through the study of the "incestuous king" in the histories of sacred monarchies; $V \& S, 257)$. If plagues, mythical or real, entail the perception of an endemic spreading of collective violence, then it is necessary to determine if literary (Lucretius, Boccaccio, Shakespeare, Defoe, Thomas Mann etc.) and historical testimonies ${ }^{6}$ can confirm this standpoint. This is exactly the question that Girard will investigate in his 1974 paper "The Plague in Literature and Myth" . This will also be a pivotal aspect in Girard's analysis of Guillaume de Machaut's poem in the opening chapters of The Scapegoat.

\footnotetext{
${ }^{6}$ See, for instance, the 1697 testimony of the Portuguese monk Fco de Santa Maria $(S, 13)$.

7 René Girard,"The Plague in Literature and Myth". Texas Studies in Literature and Language 15, no. 5 (1974): 833-850.
} 


\section{Myths and "texts of persecution"}

The idea of a comparative study of myths and medieval texts of persecution was first introduced by Girard in 1978 in Things Hidden Since the Foundation of the World ${ }^{8}$. In this volume, we discover that from the structural elements of historical documents is easy to infer the scapegoat mechanism as a text referent. Girard argues that, while this approach is commonly accepted in the logic of drawing facts from historical documents, it is arbitrarily dismissed for the study of ancient myths. A few years later, in The Scapegoat, Girard allowed us a more detailed account, and respectfully so, to this novel vindication of his own methodology.

At first glance, Girard seems to introduce his new approach as a clarification of his initial method. Now, as we shall see, it is more accurate to discuss the emergence of a third methodological axis. While the continuity between Girard's first studies on the Oedipus myth and The Scapegoat is conspicuous from a structural point of view, it should be noted that Girard introduced the features of his symmetry-dissymmetry reading of Greek tragedies in a clearer and more concise manner. The Scapegoat demonstrates how Girard condensed his first approaches and findings into a clear-cut list of "stereotypes of persecution" $(S, 12-23)$. However, the novelty of the approach should not be underestimated. For Girard now calls for cross-historical and cultural categories that are grounded in statistics, global coherence, and abduction. From this angle, the comparative study of myths and texts of persecution provide additional evidence based on new and independent methodological principles.

\section{A. "Stereotypes of Persecution"}

The continuity between Girard's first studies on Sophocles' play and the "stereotypes of persecution" can be easily explained. The first stereotype is one of crisis - namely the loss of cultural and social differences triggered by the increasing reciprocity, or symmetry, between people $(S, 12-14)$. This crisis can be launched by several phenomena such as an epidemic, a starvation, political or social dissensions, etc. The second stereotype establishes the link between this initial crisis and the charges put against the victim(s). The loss of differences needs to be mirrored in the alleged "crimes" committed by the victim(s). To put it differently, the second stereotype designates "crimes that eliminate distinctions" $(S$, 21). As Girard puts it: "All these crimes seem to be fundamental. They attack the very foundation of cultural order, the family and the hierarchical differences without which there would be no social order." $(S, 15)$. Incest, parricide, the transgression of major cultural or religious taboos are all examples of the crimes of undifferentiation mentioned by Girard. The third stereotype directly concerns the victim. It encompasses all the arbitrary and distinctive traits that differentiate the accused victim. These characteristics can rest on cultural or religious considerations, such as the victim's belonging to a minority; on physical appearance, like anillness, madness, handicap, conspicuous deformities etc.; or on social status aspects, the beggar occupying the same risky and marginal role as kings or men of high power, for example. Through the third stereotype, argues Girard, the victim can appear as undifferentiation personified $(S, 21-22)$, that is as someone threatening the whole system of collective violence from the outside. The fourth stereotype is "violence itself". As Girard explains: “ ... the import of the operation is to lay the responsibility for the crisis on the victims and to exert an influence on it by destroying these victims or at least by banishing them from the community they " pollute'." ( $S$, 24). As it has been mentioned already, the chaos which depends on the crowd's for creation and responsibility

\footnotetext{
${ }^{8}$ René Girard, Des choses cachées depuis la fondation du monde (Paris: LGF, 1983) 171-179.
} 
nonetheless appears to it as an external threat. A sufficiently marginalized person targeted by the accusation of undifferentiation can thus appear in an illusory way as the original cause of the crisis. Hence, we find the same elements in Girard's previous studies where Oedipus embodied the actual symmetry of all characters but on the deceitful level that is dissymmetry. By introducing the "stereotypes of persecution", Girard managed to make his analysis of the myth more synthetic and easier to understand. Through a series of wise choices regarding the exposition of his theory, Girard condenses into two paragraphs what his previous studies intended to establish:

The plague is ravaging Thebes: here we have the first stereotype of persecution. Oedipus is responsible because he has killed his father and married his mother: here is the second stereotype. The oracle declares that, in order to end the epidemic, the abominable criminal must be banished. The finality of persecution is explicit. Parricide and incest serve openly as the intermediaries between the individual and the collective; these crimes are so oblivious of differences that their influence is contagious to the whole society. In Sophocles' text we establish that to lack difference is to be plague-stricken.

The third stereotype has to do with the signs of a victim. The first is disability: Oedipus limps. This hero from another country arrived in Thebes unknown to anyone, a stranger in fact if not in right. Finally, he is the son of the king and a king himself, the legitimate heir of Laius. Like many other mythical characters, Oedipus manages to combine the marginality of the outsider with the marginality of the insider. $(S, 25)$

As for the fourth stereotype ("violence itself"), we can find it at the very beginning of the play. It is the peculiar distortion of the persecutory perspective for which the alleged crimes of a single person can equal the damages of a major epidemic such as the plague. Thus, Girard re-accommodated the pivotal elements of his first studies of Sophocles' play in a more economical way.

Until now, the innovations of his approach introduced in The Scapegoat have not been acknowledged. This is what we shall discuss now.

\section{B. On the logic of drawing history from ancient myths}

Stereotypes of persecution are involved in concrete and observable episodes of collective violence. Let us consider two examples introduced by Girard himself. In the execution of Marie-Antoinette by guillotine we can identify: (1) the crisis - namely the loss of differences involved by the general circumstances of the French Revolution; (2) the queen was accused "of having committed incest with her son" $(S, 20)$ - that is, she was accused of a crime which eliminated distinctions; (3) Marie-Antoinette is differentiated through her political status and her foreign Austrian origins; (4) her execution is proclaimed by a court "heavily influenced by the Parisian mob" $(S, 20)$ - that is, the crowd seeks to discharge the causes of the crisis on a single person. The second example is about a violent crowd executing a black male for having raped a white female $(S, 20-21)$. Here again the marginalized person embodies, through his crime, the undifferentiation that is in the persecutors' eyes. This is at the origin of the collective state of crisis. The two examples show the relevancy of the stereotypes of persecution for situations where the persecutors' viewpoint can directly be related with the actual acts of violence. The examples also show that the surrogate victim can be responsible for a criminal act. However, what matters for 
Girard is the observable disproportion between the real crime and the violent unanimity of the crowd mistaking an isolated transgression for the causal element of the collective chaos.

That being said, why should we, as Girard argues, extend this whole approach to the study of ancient myths? Let us try to solve this issue step by step. Right from the start, we have two elements: (1) for cases in which we have all the factual knowledge at hand, we can state that the stereotypes of persecution are structural elements entailing a statistical reliability, that is, we can observe that the obvious structural features are correlated with actual psychological and social scapegoating mechanisms; (2) taken as a testimony, the viewpoint of the persecutor is neither entirely realistic, nor entirely imaginary — as Girard puts it: "the probable and improbable interact in such a way that each explains and justifies the presence of the other" $(S, 7)$. This latter aspect requires further explanations. On the one hand, testimony from within a phenomenon of collective violence is not false to the extent that the crisis entails the loss of social and cultural differences and that the surrogate victim is perceived as responsible for this state of undifferentiation. On the other hand, the testimony is not realistic to the extent that the substitution mechanism rests on the crowd's ignorance. In brief, the testimony is a distorted viewpoint with respect to a real event. Now, if we separate the probable from the improbable aspects, we risk encouraging two types of mistakes. In the early modern period, witch hunts $(S, 9-11)$ were based on a legal perspective. If we overestimate the plausibility of legitimate legal proceedings, then we adopt the persecutors viewpoint. If we just take into consideration the improbable aspects of the testimony, then we will have to raise doubts on the reality of the related events in its entirety. The first mistake would put into question the historian's gullibility, while the second one would put into question his extreme skepticism. Eventually, the reading of the events in terms of stereotypes of persecution appears as the most moderate and reasonable option. For, to exclusively highlight the plausible or implausible elements of a testimony strictly depends on personal preferences. Girard contends that a higher objectivity implies considering the entirety of all elements included in the testimony. It is a holistic reading of the text which guides the historical approach. The vindication of such a method appears in the very first pages of The Scapegoat.

In a context of improbable events, those that are possible become probable. The reverse is also true. In a context of probable events, the unlikely ones cannot be ascribed to an imagination operating freely for the pleasure of inventing fiction. We are aware of the imaginary element, but it is the very specific imagination of people who crave violence. As a result, among the textual representations there is a mutual confirmation. This correspondence can only be explained by one bypothesis: the text we are reading has its roots in a real persecution described from the perspective 'of the persecutors. The perspective is inevitably deceptive since the persecutors are convinced that their violence is justified; they consider themselves judges, and therefore they must have guilty victims, yet their perspective is to some degree reliable, for the certainty of being right encourages them to hide nothing of their massacre." ( $S$, 6. Italics added).

Now, the question is the following: how shall we interpret texts which, albeit less clear regarding the specific circumstances of the related events, are nonetheless characterized by the same structural elements that are the same stereotypes of persecution? If, for instance, we value the improbable elements, then we would not only express our personal preferences, or favor our preconceived hypotheses, but we would also ignore the strong statistical correlations between stereotypes of persecution and actual acts of violence. Thereby, argues Girard, the ideal standards of probability and objectivity do much more 
than encourage us to use ampliative logic, that is a logic which instead of deducing what is contained in our premises goes beyond them by adding a new form of knowledge. The fact that we observe an expected structural identity between consistent texts of persecution and far less circumstantial texts, including ancient myths, appeals to a novel hypothesis. Girard's reasoning is as follows: (1) the surprising regularity of stereotypes of persecution is observed among historical documents and mythical texts; (2) but, if the scapegoat hypothesis were true, this regularity would be a matter of fact; (3) hence, there is reason to believe that the scapegoat hypothesis is true. This type of reasoning is what contemporary philosophy of science calls "inference to the best explanation". Charles Sanders Peirce named this type of inference abduction, as distinct from induction and deduction. Contrary to deduction, induction and abduction go beyond what is initially contained in the premises (i.e. both are ampliative). While "Induction seeks for facts", "Abduction seeks a theory" $(O L D H, 106)$. In other words, while the ampliative logic of induction is solely concerned by statistics or observed frequencies, the ampliative logic of abduction is concerned by explanatory considerations. Now these considerations are precisely a key aspect of Girard's work. Indeed, he accounts for an unexpected regularity between myths and specific historical documents. Thereby, he needs to proceed to the uniformization, and/or, rationalization of the facts. As Peirce states: "The mode of suggestion by which, in abduction, the facts suggest the hypothesis is by resemblance,- - the resemblance of the facts to the consequences of the hypothesis." $(O L D H, 106)$. This resemblance is suggested at a cross- historic and cross-cultural scale when we consider that specific and observable structural elements in both mythic texts and historic documents can be considered as consequences of a psycho-social scapegoat mechanism.

To sum up, the vindication of Girard's methodology in The Scapegoat can be divided in five steps: (1) from a statistical or probabilistic viewpoint, stereotypes of persecution are strongly correlated with unambiguous, evidenced and observable, cases of scapegoating; (2) due to psychological effects of distortion, texts of persecution include at the same time probable and improbable elements; (3) thus, the exclusive valuing of probable or improbable elements in such kinds of testimonies would rest on a matter of personal preferences; (4) to refuse the possibility of violent acts behind myths amounts to neglect the aforementioned aspects; (5) given the structural identity of texts of persecution and ancient myths, and given the strengths of our common interpretation of the former, the scapegoat mechanism appears as the best explanation with respect to the stereotypes of persecution included in myths.

However, two further aspects are worth being mentioned. First, myths nonetheless have a significant difference with respect to, for instance, Middle Ages' texts of persecution. For in myths, according to Girard, victims become sacred. Being at the same time responsible for the collective violence and for its ending, the surrogate victim will finally appear as a threatening and beneficial divinity. To account for the loss of the sacred in standard persecution texts, Girard included the hypothesis of the progressive weakening of the scapegoat mechanism in his theoretical framework. This was a part of Girard's explanation concerning the historical and cultural role played by the Christian revelation in the unveiling of the scapegoat mechanism. And we remember that in 1985 Girard proposed a famous comparative study opposing the "Myth of Oedipus" with "the truth of Joseph" (OU, 107-114).

The second aspect is about Girard's attitude regarding the idea of real events concealed or distorted through mythic or historic texts. The ampliative logic of The Scapegoat frequently aims to show how the scapegoat mechanism can be inferred from the most to the least detailed of testimonies. For instance, the case of Marie-Antoinette is welldocumented. However, we apply the same reasoning and methods of conviction for witch 
trials, where evidence is often scarcer. For Guillaume de Machaut's poem, the Judgement of the King of Navarre, we do not have information regarding the specific circumstances of the events, but we can draw important conjectures from our knowledge of the historical context, for example the fear of the Black Death and the scapegoating of Jews in Medieval communities $(S, 1-11)$. For the myth of Oedipus or other ancient tales, we do not have the possibility to draw historic conjectures like in the previous case. Here we proceed to logical abduction at its purest level. However, does it mean that a precise textual pattern of representations of persecution necessarily implies the occurrence of a real persecution? Certainly not, for it would be a caricatured version of Girard's methods and theories. The first thing to consider is that texts and tales keep their notable features through multiple transmissions. Sophocles, as we know, did not invent the Oedipus myth. Yet, he reexplored the story within its constitutive persecutory frame. As well, Girard is perfectly aware that we cannot at the same time extend a method and deny its initial margin of error. We will indeed encounter texts where the stereotypes of persecution, albeit present, remain purely artificial. However, what matters is the strong, not absolute, correlation of those stereotypes with actual violent events. In The Scapegoat, Girard proposes a small thought experiment where the Oedipus myth is rephrased in a shorter version taking place "in some part of the Christian world between the twelfth and thirteenth centuries" $(S, 29)$. For this amended version, asks Girard, would we make the very inference which is arbitrarily foreclosed for the study of ancient myths? Would we infer the presence of a scapegoat mechanism?

Harvests are bad, the cows give birth to dead calves; no one is on good terms with anyone else. It is as if a spell had been cast on the village. Clearly, it is the cripple who is the cause. He arrived one fine morning, no one knows from where, and made himself at home. He even took the liberty of marrying the most obvious heiress in the village and had two children by her. All sorts of things seemed to take place in their house. The stranger was suspected of having killed his wife's former husband, a sort of local potentate, who disappeared under mysterious circumstances and was rather too quickly replaced by the newcomer. One day the fellows in the village had had enough; they took their pitchforks and forced the disturbing character to clear out. $(S, 29)$

When asked, we might instinctively describe this story as a representation of the scapegoat hypothesis. For this explanation accounts for all the elements that can be found in the text. Thereby, Girard aims to question the methodological prohibitions instituted by modern anthropology: why should we restrict the possibility to infer a textual referent to historical documents only? Could it be the case that we overvalue the distinctiveness of ancient myths? Should we not say that we create artificial differences based on the most anecdotal details? However, Girard is aware that his example could naively be interpreted as a direct refutation of his method:

Even if the Dogrib myth were not the result of actual collective violence it would be the work of a competent imitator, capable of reproducing the textual effects of this type of violence; it would therefore still provide a valuable example like my false myth of Oedipus. If I were to assume there was a real victim behind the text I have just invented I would be making a huge mistake, but my error would not, in fact, be any less faithful to the truth of the majority of texts containing the same stereotypes and similar structure. It is statistically inconceivable that all these texts could have been forgeries. $(S, 51-52)$ 
Textual mechanisms can be deceptive, but this very fact, Girard contends, shows us that peculiar patterns tend to suggest specific explanations. These suggestive effects do not come out of nowhere, but depend on the known and experienced statistical pertinence of our conjectures with respect to texts of persecution. If our guessing instinct can be tricked, this doesn't imply that we should never put trust in our guesses. According to Girard, it is more accurate that our inferences of scapegoat mechanisms are so frequently relevant that we can sometimes be tricked by "forgeries". Hence, this approach implies a limited and reasonable margin of error whose existence he never denied.

\section{Incest, parricide and the issue of judicial evidence}

Girard knew that his novel theories on the origins of human culture were not to be proved in the most direct way. The violent facts standing behind mythical texts are not objects of observation. It should rather be said that the hypothesis of violent origins is sustained by a multiplicity of indirect clues. Therefore, Girard sometimes expressed his interest regarding the status of evidence in police investigations and legal proceedings. In both fields, indirect clues are highly useful and highly estimated. Instead of expecting immediate confirmations, argues Girard, anthropology should select more suitable evidential standards. That is why he sometimes puts emphasis on the commonalities between his approach and the legal or investigatory perspectives:

In terms of judicial evidence, it is also true that the fact that evidence has been erased may work as a super-proof, a meta-evidence because it shows the crucial importance of the element that has been erased. If someone removes the traces of a murder, it means that he is strongly implicated in it. ${ }^{9}$

That being said, shall we consider that Girard's method is that of a judge or of a detective? Starting with witch trials, many scapegoating phenomena are grounded in legal proceedings. A purely judicial perspective may sometimes be detrimental to the correct identification of the distortions that we use to find in texts of persecution. Besides, archaic societies were deprived of a proper judicial system. In this context, the issue of vengeance must be anticipated and acknowledged differently. Still not unveiled through the Christian revelation, the "scapegoat mechanism" is "more effective ... than our own" $(S, 42)$. That is, unawareness regarding the existence and nature of the mechanism makes it function at the most fundamental level. The polarization of collective violence on a single victim reaches its highest degree of spontaneity because the belief in the victim's guilt is immediate and absolute. The modes of accusation in the middle ages are less direct. The scapegoat mechanism begins to be manipulated and adulterated, and consequently, the sacralization of the victim weakens. The blame put on the victim must be reconciled with the appearances of justice. Superstitions still play a significant role, but they need to be supplemented by further strategies and (weak) demands of rationality, for example when Guillaume de Machaut rationalizes his accusation by claiming that Jews poisoned the rivers ${ }^{10}$. Hence, Girard postulates a historical shift in the styles of accusation that he explicitly relates with the Oedipus myth:

\footnotetext{
9 René Girard, Evolution and Conversion: Dialogues on the Origin of Culture (New York: Continuum International Publishing, 2008), 185.

10 "Admittedly, the victim is condemned in advance; he cannot defend himself, his trial has already taken place, but at least there is a trial no matter how prejudiced. The witches are hunted legally; even the persecuted Jews are explicitly charged, charged with crimes that are less unlikely than those of the mythical heroes. The desire for relative probability which conjures up "the poisoning of rivers;'
} 
In historical persecutions the 'guilty' remain sufficiently distinct from their 'crimes' for there to be no mistake about the nature of the process. The same cannot be said of myth. The guilty person is so much a part of his offense that one is indistinguishable from the other. His offense seems to be a fantastic essence or ontological attribute. In many myths the wretched person's presence is enough to contaminate everything around him, infecting men and beasts with the plague, ruining crops, poisoning food, causing game to disappear, and sowing discord around him. [...] If the myth were to state 'Undoubtedly Oedipus killed his father; it is certain that he had intercourse with his mother'; we would recognize the type of lie it embodies; it would be written in the style of historical persecutors, from a basis of belief. But it speaks tranquilly of an unquestionable fact: 'Oedipus killed his father; he had intercourse with his mother,' in the same tone one would say: 'Night follows day' or 'The sun rises in the East'. $(S, 36)$

As already mentioned, Oedipus radically embodies undifferentiation (I.B.). This is precisely why his "crimes" violate natural laws and are perceived as the root cause of the Theban epidemic. One has to acknowledge that this type of accusation is unsound from a more modern judicial perspective.

Furthermore, it has often been noticed that Oedipus Rex can be considered as an early prefiguration of modern crime novels. The reader is invited to follow an investigation on Laius's murder. Witnesses are summoned, the circumstances of the crime are re-explored, and, at least in the first parts of the play, everyone is treated with an equal degree of suspicion. In Violence and the Sacred, Girard insisted on the scarcity and inherent fragility of the evidence put against Oedipus. The investigation's conclusion rests on a single detail:

If we eliminate the testimony brought against Oedipus in the second half of the tragedy, then the conclusion of the myth, far from seeming a sudden lightning flash of the truth, striking down the guilty party and illuminating all the mortal participants, seems nothing more than the camouflaged victory of one version of the story over the other, the polemical version over its rivalthe community's formal acceptance of Tiresias's and Creon's version of the story, thereafter held to be the true and universal version, the verity behind the myth itself. ( $V \ll S, 73)$

Now, let us put aside the fact that Oedipus cannot be held responsible for the Theban plague. Should we state that he can be judged guilty of incest and parricide beyond a reasonable doubt? On this matter, Girard's seems to favor a skeptical attitude. With respect to the continuous and mutual accusations, as well with respect to the personal interests motivating each character, that is Oedipus's will to keep the throne, Creon's quest for political power, Tiresias's rivalry with the Theban hero who defeated the Sphinx, then the proof given by the messenger at the end of the tragedy might not be as conclusive as it first seems. As Mark Anspach puts it: "If Oedipus is a detective story, Girard is a meta-detective who sniffs out the evidence of mob violence hidden behind the surface details of the narrative." (OU, xvi). Relying on Frederick Ahl's essay Sophocles 'Oedipus: Evidence and Self-

paradoxically helps us to make the distinction between truth and falsity. Mythology demands the same operation, though in a more daring form because the circumstances are more confused." $(S, 36)$. 
Conviction ${ }^{11}$ and on other sources, Anspach demonstrates to what extent this investigative approach can be supplemented. Let us summarize Anspach's reasoning. Concerning the murder of King Laius, it appears that specific details related to the crime are scarce. We know that Laius has been killed on his way to Delphi. In the second episode of Sophocles's play, Oedipus recalls his memories to Jocasta. Years ago, he decided to leave Corinth in order to escape the tragic prophecy from the oracle of Delphi. On his way, he met an old man on a chariot followed by his servants. The group violently urges him to step outside of their road. After a fight between the two parties, only Oedipus is left standing. For the official interpretation of the play, the guilt of the tragic hero is evidenced by this painful avowal. Now, we should not assume that, unknowingly, Oedipus was relating the events leading to Laius's murder. What we know is that he killed an "unidentified old man and 'all' the members of his party" (OU, xxi). But we cannot say with absolute certainty that this man was Laius. For Oedipus's testimony contradicts the depiction of the killing of Laius in at least two respects: (1) the Oracle's message transmitted by Creon explicitly mentions the involvement of multiple murderers (OR, line 106) and Oedipus also believes that a correct account on the number of assailants might exonerate him (OR, 1. 843-845); (2) at the end of the play, we know that at least one eye-witness survived — which directly contradicts Oedipus's own recollections of the event. In other words, one person cannot equate many persons and "All save one cannot be equal to all." (OU, xxi). Besides, the famous messenger in Sophocles's play is not an official representative, but a witness seeking a financial reward (OR, 1. 1004-1007). Thus, we might be confronted with an adulterated or corrupted testimony. Yet, one may retort that we know the story of the dismissal and violent treatment of Jocasta's baby which, at first glance, bears strong resemblances with Oedipus's own tragic past. However, Oedipus's abandonment, as well as his handicap cannot be considered as a solid evidence regarding the alleged kinship. Although Oedipus interprets this last piece of information as the definitive proof of his own guilt, it is worth mentioning that his inferences turn out to be inconsistent. For even if we suppose that Oedipus had intercourse with his mother, there still would not be any necessary connection between this "fact" and the act of parricide (OU, xxii). Eventually, these puzzling aspects tend to confirm Girard's idea that mythical accusations are more direct and spontaneous than judicial ones, even if both modes of accusations can involve a scapegoat mechanism.

\section{Girard, Whewell and Pierce}

In this last part, let us address some specific questions with respect to Girard's mimetic theory and his interpretation of the Oedipus myth. First, we will show how William Whewell's method of consilience might help us to understand the way in which Girard vindicated the evidence in support of his lectures of ancient myths. Secondly, we aim to highlight some commonalities between Charles Sanders Peirce's views of the historical sciences and Girard's anthropological methods.

\section{A. Mimetic theory and consilience}

According to the philosopher William Whewell, when it comes to test the strength of a new theory the "consilience" of inductions, along with prediction and coherence, is one of the most valuable methods. In consilience, as Laura J. Snyder observes: "the causal law is not imposed from above as a means of tying together different event kinds. Instead, it wells

${ }^{11}$ Frederick Ahl, Sophocles 'Oedipus: Evidence and Self-Conviction (New York : Cornell University Press, 1991). 
up from beneath in each separate case. ${ }^{12 "}$ Newton, for instance, found that separate inductions regarding circumjovial orbits, planetary orbits, and falling bodies were pointing towards the same direction. A series of distinct inquiries showed the relevancy of a specific "causal unification"13". For Whewell, the strength of the universal law of an inverse-square attractive force precisely depends on this intrinsic convergence of multiple clues. The homogenization of natural phenomena introduced by the theory does not rest on subjective preferences but is encouraged by the unexpected intertwining of different results. Whewell perceived this nearly endogenous development of novel and fruitful causal assumptions as the best sign of solid scientific evidence:

No accident could give rise to such an extraordinary coincidence. No false supposition could, after being adjusted to one class of phenomena, exactly represent a different class, where the agreement was unforeseen and uncontemplated. That rules springing from remote and unconnected quarters should thus leap to the same point, can only arise from that being the point where truth resides. ${ }^{14}$

Whewell's statement is of peculiar interest for our discussion. The method of consilience, indeed, tends to show that what Girard sometimes perceived as being the main difficulty of his theory can actually be considered as its major strength:

I think that the elements favorable to my thesis are too numerous and consistent to be disputed, but any of those taken by themselves cannot be regarded as a veritable proof. It is the multiplicity of consistent elements that constitutes proof..$^{15}$

During our study of Girard's lecture of the Oedipus myth, we noticed four methods of inquiry: (1) the common-sense identification of sacrificial substitutions; (2) the careful analysis of symmetries and dissymmetries in mythological texts; (3) the study of crosscultural and cross-historical persecution stereotypes; (4) the application of the common standard of evidence, guilty beyond a reasonable doubt, for criminal conviction. With the exception of the third inquiry, which depends on the second, all the approaches independently provide valuable clues "leaping to the same point", namely the scapegoat hypothesis. Hence, indirect evidence does not necessarily imply an epistemic weakness with respect to anthropology. For it is the striking convergence of indirect evidence towards the same direction which constitutes the most solid proof.

According to Whewell, another important confirmation criterion is coherence. As Laura J. Snyder observes, "coherence can be seen as a type of consilience that happens over time ${ }^{16 "}$. It is worth mentioning that Whewell himself acknowledged that consilience and coherence possess a strong affinity ${ }^{17}$. The Victorian philosopher noticed an important aspect regarding the evolution of scientific theories:

... we have to notice a distinction which is found to prevail in the progress

of true and false theories. In the former class all the additional suppositions

\footnotetext{
12 Laura J. Snyder. Reforming Philosophy: a Victorian Debate on Science and Society (Chicago: University of Chicago Press, 2006), 175.

13 Ibid., 174.

14 William Whewell. Novum Organon Renovatum (London: John W. Parker and Sons, 1858), 88.

15 René Girard, Evolution and Conversion: Dialogues on the Origin of Culture, 160. Italics added.

16 Laura J. Snyder, "William Whewell", The Stanford Encyclopedia of Philosophy, ed. Edward N. Zalta, (2002): URL $=<$ https://plato.stanford.edu/archives/win2012/entries/whewell/ $>$.

17 William Whewell. Novum Organon Renovatum, 95.
} 
tend to simplicity and harmony; the new suppositions resolve themselves into the old ones, or at least require only some easy modification of the hypothesis first assumed: the system becomes more coherent as it is further extended. The elements which we require for explaining a new class of facts are already contained in our system. Different members of the theory run together, and we have thus a constant convergence to unity. In false theories, the contrary is the case. ${ }^{18}$

While false theories need to multiply ad hoc hypotheses over time to account for unexpected facts or events, true theories appear able to account for those events or facts without changing their initial suppositions in an important way. Now, it is conspicuous that the argument of coherence played a key role in Girard's defense of his interpretation of the Oedipus myth. For he did not only wish to prove that his interpretation is the best one with respect to Sophocles' play; he also wished to show that his reading of the myth is able to account for other surprising facts or events without a modification of the initial suppositions. As we already mentioned, it is Girard's contention that the myth of Oedipus informs us about the way archaic societies conceived sacred monarchies and also about the way human societies generally tend to portray their state of inner chaos. For example, his reflections on the plague as a contagious and mimetic spreading of human conflict.

\section{B. Mimetic theory and C.S. Peirce's views of the historical sciences}

Girard's studies on the cross-cultural and cross-historical persecution stereotypes do not entirely rest on consilience. A different and more peculiar method is at play here. As already mentioned, Girard's reasoning in The Scapegoat is partly based on the idea of abduction which was first introduced by philosopher Charles Sanders Peirce (II. B.). In his 1901 paper "On the Logic of Drawing History from Ancient Documents", Peirce is questioning the relevancy of the standard evaluation of testimonies introduced by David Hume in his essay "Of miracles" 19 . In brief, Hume stated that in the case of problematic testimonies, we shall weigh the probability of the related event against the probability that the witness does not tell the truth. According to Peirce, this theory of balancing likelihoods can rarely be applied in a satisfactory way by historians because the sufficient conditions and elements for such a probable reasoning will often not be at hand. In addition, probability is a statistical matter. Now, argues Peirce, historians do not want to know the global likelihood of the truth of someone's testimonies; they want to know if a specific testimony is or is not accurate. If the witness supposedly has a $95 \%$ likelihood to tell the truth, then we do not know if his current testimony belongs, or not, to the remaining $5 \%$ of non-reliable statements. Put otherwise, the theory of balancing likelihoods does not address the questions which matter for historians. While our chances to win a game of dice can be estimated in accordance with a law of probability, a series of different statements made by a witness entails heterogenous topics and contexts that cannot be subsumed under such a general principle $(O L D H, 81-82)$. Furthermore, by ignoring the aforementioned difficulties, some historians (Peirce's target is the exaggerated skepticism of the German classical philologists of his time), are convinced to use a rigorous scientific method, although they are actually just presenting their subjective preferences as probabilities.

\footnotetext{
18 Ibid., 91.

${ }^{19}$ David Hume, Enquiries Concerning Human Understanding and Concerning the Principles of Morals (Oxford: Oxford University Press, 1975), 109-131.
} 
Peirce states that the theory of balancing likelihoods puts aside the role of abduction in historical sciences. According to him, historians, at least most of the time, are not able to assess the probability of a related event. However, they can try to seek the best explanation for the testimony under study. Hence, the "first rule", states Peirce, should be the following: "our hypothesis ought to explain all the related facts. It is not sufficient to say that testimony is not true; it is our business to explain how it came to be such as it is." $(O L D H, 113)$. This rule can obviously be paralleled with Girard's approach. It is worth remembering that Girard accounts for all the elements in texts of persecution and myths. In this context, he argues, the scapegoat hypothesis has the greatest explanatory power for it permits us to see how the probable and improbable aspects of the testimony are connected to the violent and distorted perspective of the oppressors. To solely favor the plausible or implausible features of these texts would be a mere matter of personal preferences. And we could add, following Peirce, that it would be an inadequate application of the theory of balancing likelihoods.

Peirce's intention was not to state that probabilities should not play any role in the logic of drawing history from testimonies. More specifically, and not to forget: (1) as already mentioned, the theory of balancing likelihoods must not be misapplied or overestimated in the field of historical studies; (2) regarding our natural attitudes towards testimonies, the use of probabilities mainly arbitrates our decisions in a second stage. We do not weigh the pros and cons immediately and automatically. Our first attitude is to put some trust in what people are telling us. We began to think in terms of probabilities only when the tale begins to pose some problems relative to our expectations and understanding. Thus, the theory of balancing likelihoods will sometimes guide the historian's decisions but under specific conditions:

... probabilities that are strictly objective and at the same time very great, although they can never be absolutely conclusive, ought nevertheless to influence our preferences for one hypothesis over another; but slight probabilities, even if objective, are not worth consideration; and merely subjective likelihoods should be disregarded altogether. For they are merely expressions of our preconceived notions. Now one of the main purposes of studying history ought to be to free us from the tyranny of our preconceived notions." (OLDH, 114)

Girard is precisely forming his hypotheses through abduction and using objective probabilities as a guide. Myths are indeed puzzling stories for us. We cannot have a thoughtless or uncritical attitude towards them. However, we can account for all the elements that appear in them with the aid of conjectures that turn out to be statistically reliable in the case of historical persecution testimonies. The demystification of ancient religions is grounded on an inference to the best explanation which ought to be favored or selected based on probabilistic considerations.

\section{Conclusion}

It shall be noted that this paper is exploratory and that it entails several limitations. A more detailed comparison between Girard's methods, as well as Whewell's and Peirce's epistemologies, would require a distinct study. Relative to Whewell's conception of science, the use and status of induction in Girard's anthropology deserves to be discussed. Possibly, René Girard had a slightly different understanding of consilience than Whewell. Perhaps Girard was closer to the broader and more contemporary understanding of consilience 
having in mind, as does Edward $\mathrm{O}$. Wilson ${ }^{20}$, the general task of the unification of knowledge. From the perspective of Peirce's philosophy of science, an interesting question would be to see how the economic aspects ("cost", "value", "effects upon other projects") of Girard's hypotheses could be vindicated. Besides, the focus of our study was Girard's interpretation of the Oedipus myth. Now, as Girard acknowledges, this myth is particularly useful for introducing the mimetic theory in the most coherent and pedagogic way ${ }^{21}$. Other myths pose difficulties with respect to their interpretation because the stereotypes of persecution, albeit present, appear less obvious. In these cases, the possibility of additional methods cannot be excluded. It is worth mentioning that Girard sometimes expressed the regret that he insisted too much on the Oedipus myth. While the deconstruction of the myth certainly shows the strengths of the mimetic theory and while Girard developed some of his most pivotal hypotheses through his studies on Sophocles's tragedy, the conclusion following from his approach is very different from Freud's. Far from being culturally repressed, incest and parricide are common stereotypes of persecution in ritual and myths; the story of Oedipus does not have a special status but exemplifies (in a clear and striking way) a scapegoat mechanism which lies at the core of every myth ${ }^{22}$.

However, we believe that our study leaves us with interesting questions regarding René Girard's mimetic theory. It is important to notice the significant differences between Whewell and Peirce's epistemologies. As Laura J. Snyder reminds us, consilience and abduction are not the same concepts. The notion of consilience is grounded on the idea of a "convergence of distinct lines of argument ${ }^{23}$ ". Said differently, distinct and independent discoveries are leading us, nearly immanently, towards the same conclusion or result. In the case of abduction, on the contrary, the uniformization or rationalization of events is imposed from above. Here we suspect that if some explanation (x) were true, then the surprising class of events or facts (y) that we observed would be a matter of course. For Whewell, consilience appears as a final test regarding the scientific nature and consistency of a given theory, whereas for Peirce abduction is mainly the first step for scientific research (i.e. explanatory considerations help us to generate hypotheses which must lead to deducible and testable results). Situated in between consilience and abduction, René Girard's epistemology consequently appears as a hybrid or composite approach. For future research on Girard's mimetic theory, an interesting aspect would certainly be to determine whether and how such an approach can be vindicated. And if this hybrid approach turns out to be too problematic, an important question would immediately arise: between consilience and abduction, which conception should count as the mimetic theory's epistemological cornerstone?

\section{References}

Ahl, Frederick. Sophocles 'Oedipus: Evidence and Self-Conviction. New York: Cornell University Press, 1991.

Anspach, Mark. CEdipe Mimétique. Paris: L’Herne, 2010.

Girard, René. "The Plague in Literature and Myth". Texas Studies in Literature and

Language 15, no. 5 (1974): 833-850. . Violence and the Sacred. Baltimore: Johns Hopkins University Press, 1977.

\footnotetext{
${ }^{20}$ Edward O. Wilson, Consilience: The Unity of Knowledge (New York: Vintage Books, 1999).

21 Girard recognized that the Oedipus myth is "exemplary in regard to representations of persecution." $(S, 30)$.

${ }^{22}$ See for example Mark R. Anspach, Edipe Mimétique, "Entretien avec René Girard”, 20-22.

${ }^{23}$ Laura J. Snyder. Reforming Philosophy: a Victorian Debate on Science and Society, 175.
} 
Des choses cachées depuis la fondation du monde. Paris: LGF, 1983.

The Scapegoat. Baltimore: John Hopkins University Press, 1986.

Oedipus Unbound: Selected Writings on Rivalry and Desire, ed. Mark R. Anspach. Palo

Alto: Stanford University Press, 2004.

Evolution and Conversion: Dialogues on the Origin of Culture. New York: Continuum International Publishing, 2008.

Hume, David. Enquiries Concerning Human Understanding and Concerning the Principle of Morals. Oxford: Oxford University Press, 1975.

Peirce, Charles Sanders. "On the Logic of Drawing History from Ancient Documents, Especially from Testimonies”. In The Essential Peirce, Vol. 2, ed. the Peirce Edition Project, 75-114. Bloomington: Indiana University Press, 1998.

Snyder, Laura J. Reforming Philosophy: a Victorian Debate on Science and Society. Chicago:

University of Chicago Press, 2006.

. "William Whewell". The Stanford Encyclopedia of Philosophy, ed. Edward N. Zalta,

(2002): URL $=<$ https://plato.stanford.edu/archives/win2012/entries/whewell/>.

Sophocles, Oedipus Rex, tr. R.D.Dawe. Cambridge: Cambridge University Press, 2006.

Whewell, William. Novum Organon Renovatum. London: John W. Parker and Sons, 1858.

Wilson, Edward O. Consilience: The Unity of Knowledge. New York: Vintage Books, 1999.

\section{List of Abbreviations}

OLDH: Peirce, Charles Sanders. "On the Logic of Drawing History from Ancient Documents, Especially from Testimonies". In The Essential Peirce, Vol. 2, ed. the Peirce Edition Project, 75-114. Bloomington: Indiana University Press, 1998.

OR: Sophocles, Oedipus Rex, tr. R.D.Dawe. Cambridge: Cambridge University Press, 2006.

OU: Girard, René. Oedipus Unbound: Selected Writings on Rivalyy and Desire, ed. Mark R.

Anspach. Palo Alto: Stanford University Press, 2004.

S: Girard, René. The Scapegoat. Baltimore: John Hopkins University Press, 1986.

V\&S: Girard, René. Violence and the Sacred. Baltimore: Johns Hopkins University Press, 1977.

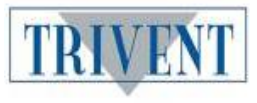

The PJCV Journal is published by Trivent Publishing. 